\title{
Air Pollutants and Frailty in Older Adults: A Geriatrician's Perspective
}

\author{
Heayon Lee, Eunju Lee, Il-Young Jang \\ Division of Geriatrics, Department of Internal Medicine, Asan Medical Center, University of Ulsan College of Medicine, Seoul, Korea
}

Many studies have provided evidence that air pollutants are harmful to humans. ${ }^{1-3)}$ Emerging data and literature from South Korea support the relationship between air pollutants and healthcare expenditure and the threat of even ambient air pollution to mortality, morbidity, and various adverse health outcomes and quality of life. ${ }^{4)}$ Through monthly balanced data using fixed and random-effect models, this study demonstrated the contributions of 5 common air pollutants to healthcare expenditure in 16 cities and provinces over 8 years (January 2010 to September 2017). The study also showed how each air pollutant affected healthcare expenditures in a particular population. Led by economists and not physicians, these findings emphasized the association between air pollutants and healthcare expenditures, indicating the urgent need for policymakers to develop effective healthcare policies.

The authors not only presented a systematic analysis of healthcare expenditure but also categorized the healthcare costs by region, demographic structure, and specific diseases. ${ }^{4)}$ One interesting aspect was their presentation of the regional minimum and maximum per-patient healthcare expenditures. The authors showed that a higher personal income level leads to higher healthcare expenditure and that per-patient healthcare expenditure increases with population age. As in other countries, older adults in South Korea are the population most vulnerable to air pollutants and environmental diseases. These reports will facilitate research on air pollutant exposure and health effects in the older population of South Korea. Moreover, life-course approaches investigating the adverse effects of air pollutants in older adults are needed. The results of these studies will highlight the urgent need for an emphasis on this topic in older populations.

However, older populations are heterogeneous, and individuals may have a wide variety of health conditions, which may result in differences in their resistance to the exposure and health effects of air pollutants. ${ }^{5,6)}$ Researchers and policymakers discussing the impact of air pollutants should consider the following characteristics of older adults: (1) vague symptoms and atypical presentation even in known specific diseases that are easily misdiagnosed as a normal aging process and which delay the diagnosis of the worsening of chronic disease or newly-onset disease; ${ }^{7)}$ (2) functional decline, including physical performance or cognition, as an early sign of health deterioration in older populations; ${ }^{8}$ (3) various aging specific symptoms and disorders known as geriatric syndromes, and their accumulation which facilitates the worsening vicious cycle in the health condition of older adults eventually leading to morbidity and mortality; ${ }^{9)}$ and (4) multimorbidity and risk of polypharmacy, which increase the risk of adverse effects and obscure the judgment of exposure. ${ }^{10,11)}$

Air pollution exacerbates poor prognoses by increasing individuals' susceptibility to diseases rather than causing direct harm to health or disease itself. ${ }^{12}$ For the reasons mentioned above, however, the effects of air pollutants on older populations cannot be judged simply by individual risk factors such as age, chronic disease, cardiovascular disease, and cognitive function. Unlike that in the general younger population, the health spectrum of the older population is varied. Even when exposed to chronic ambient air pollutants, vulnerable older individuals are more likely to have vague symptoms such as fatigue, dizziness, functional decline, and ultimately, a worsened quality of life owing to air pollutant exposure before physician diagnosis. In particular, it remains unclear if the conventional analytic method that assesses the impact of air pollutant exposure mainly based on several subtle cardiopulmonary or cognitive functions can distinguish between the effects of air pollutants and the aging phenomenon, which is eventually likely to underestimate its influence. Vulnerability in older adults can be described as a looped system formed by a linkage between vulnerable health factors; ${ }^{13)}$ therefore, the conventional risk stratification system is unlikely to be effective in older adult populations. Similar to other several diseases, a unique evaluation and risk stratification system specialized for older populations are required. ${ }^{14-16)}$

With these concerns, our researchers believe that frailty, a valuable measure of the health status of older individuals, might be the 
most suitable marker for measuring the effects of air pollutants in older populations. ${ }^{17,18)}$ This measure encompasses all age-related symptoms and disorders such as dementia, sarcopenia, insomnia, and falls, which can be used to estimate the possible effects. However, the timing and intensity of the effects on the domains are expected to vary greatly and consideration should be given to respiratory influences, nonspecific symptoms, and pathophysiology. ${ }^{2)}$ Therefore, rather than the conventional frailty index, a targeted concept and definition of frailty, namely an "air-pollutant frailty index" that reflects both the specificity of the aging physiology and the conventional known health effects of air pollutant exposure, should be developed. ${ }^{16)}$ As with human immunodeficiency virus, ${ }^{14)}$ myelodysplastic syndrome, ${ }^{19)}$ and systemic lupus erythematosus, ${ }^{15)}$ this concept of a disease-specific frailty index is also likely to be effective in vulnerable young populations. This frailty concept will serve as a compass for future fine dust studies in older adults.

\section{CONFLICT OF INTEREST DISCLOSURES}

The researchers claim no conflicts of interest.

\section{REFERENCES}

1. Moore E, Chatzidiakou L, Kuku MO, Jones RL, Smeeth L, Beevers S, et al. Global associations between air pollutants and chronic obstructive pulmonary disease hospitalizations: a systematic Review. Ann Am Thorac Soc 2016;13:1814-27.

2. Myers V, Broday DM, Steinberg DM, Drory Y, Gerber Y. Exposure to particulate air pollution and long-term incidence of frailty after myocardial infarction. Ann Epidemiol 2013;23:395-400.

3. Noh J, Sohn J, Cho J, Cho SK, Choi YJ, Kim C, et al. Short-term effects of ambient air pollution on emergency department visits for asthma: an assessment of effect modification by prior allergic disease history. J Prev Med Public Health 2016;49:329-41.

4. An J, Heshmati A. The relationship between air pollutants and healthcare expenditure: empirical evidence from South Korea. Environ Sci Pollut Res Int 2019;26:31730-51.

5. Bentayeb M, Simoni M, Baiz N, Norback D, Baldacci S, Maio S, et al. Adverse respiratory effects of outdoor air pollution in the elderly. Int J Tuberc Lung Dis 2012;16:1149-61.

6. Simoni M, Baldacci S, Maio S, Cerrai S, Sarno G, Viegi G. Adverse effects of outdoor pollution in the elderly. J Thorac Dis 2015;7:34-45.

7. Skinner TR, Scott IA, Martin JH. Diagnostic errors in older patients: a systematic review of incidence and potential causes in seven prevalent diseases. Int J Gen Med 2016;9:137-46.
8. Jung HW, Roh H, Cho Y, Jeong J, Shin YS, Lim JY, et al. Validation of a multi-sensor-based kiosk for short physical performance battery.J Am Geriatr Soc 2019;67:2605-9.

9. Kim S, Park J, Ahn H, Lee S, Yoo HJ, Yoo J, et al. Risk factors of geriatric syndromes in Korean population. Ann Geriatr Med Res 2017;21(3):123-30.

10. Kojima T. The need for actions against polypharmacy in older people with frailty. Ann Geriatr Med Res 2018;22:111-6.

11. Jang IY, Lee HY; Lee E; The 50th Anniversary Committee of Korean Geriatrics Society. Geriatrics Fact Sheet in Korea 2018 from National Statistics. Ann Geriatr Med Res 2019;23:50-3.

12. Hooper LG, Kaufman JD. Ambient air pollution and clinical implications for susceptible populations. Ann Am Thorac Soc 2018;15(Suppl 2):S64-S68.

13. Alvis BD, Hughes CG. Physiology considerations in geriatric patients. Anesthesiol Clin 2015;33:447-56.

14. Franconi I, Theou O, Wallace L, Malagoli A, Mussini C, Rockwood K, et al. Construct validation of a Frailty Index, an HIV Index and a Protective Index from a clinical HIV database. PLoS One 2018;13:e201394.

15. Legge A, Kirkland S, Rockwood K, Andreou P, Bae SC, Gordon C, et al. Construction of a Frailty Index as a Novel Health Measure in Systemic Lupus Erythematosus. J Rheumatol 2019 Apr 15 [Epub].http://doi.org/10.3899/jrheum.181338.

16. Searle SD, Mitnitski A, Gahbauer EA, Gill TM, Rockwood K. A standard procedure for creating a frailty index. BMC Geriatr $2008 ; 8: 24$.

17. Kim KJ, Shin J, Choi J, Won CW. Discrepancies in the prevalence of known frailty scales: Korean Frailty and Aging Cohort Study. Ann Geriatr Med Res 2018;22:137-44.

18. Lee H, Lee E, Jang IY. Frailty and comprehensive geriatric assessment. J Korean Med Sci 2020 [Epub]. http://doi.org/10.3346/ jkms.2020.35.e16.

19. Starkman R, Alibhai S, Wells RA, Geddes M, Zhu N, Keating MM, et al. An MDS-specific frailty index based on cumulative deficits adds independent prognostic information to clinical prognostic scoring. Leukemia 2019 Dec 6 [Epub]. http://doi. org/10.1038/s41375-019-0666-7.

Corresponding Author: Il-Young Jang, $\mathrm{MD}$

Division of Geriatrics, Department of Internal Medicine, Asan Medical

Center, University of Ulsan College of Medicine, 88, Olympic-ro 43-gil,

Songpa-gu, Seoul 05505, Korea

E-mail: dr.onezero2@amc.seoul.kr

ORCID: https://orcid.org/0000-0003-3617-3301

Received: December 8, 2019; Revised: December 17, 2019

Accepted: December 17, 2019 